\title{
Unusual progression of renal cell carcinoma with carcinomatosis peritoneii and Krukenberg tumour and alopecia with sunitinib therapy in young female
}

Manoj Pandey ${ }^{1 *}$, Mahendran Ramasamy ${ }^{1}$ and Mridula Shukla ${ }^{2}$

\begin{abstract}
Background: Sunitinib is a multiple receptor tyrosine kinase inhibitor (TKI) used for the treatment of renal cell carcinoma (RCC). It increases the median survival considerably with minimum side effects. Alopecia is one of the rare side effects. Metastasis to the ovary is also rare. We report a case of RCC metastasizing to the ovary developing alopecia early on starting sunitinib.

Case presentation: A 22-year-old hypothyroid girl underwent right radical nephrectomy for $T_{2} \mathrm{~N}_{0} \mathrm{RCC}$. Histopathology was clear cell carcinoma. Six months later, she presented with right iliac fossa pain, imaging revealed metastasis to the ileocolic junction and the ovary, an exploratory laparotomy was carried out and, after debulking, the patient was started on sunitinib. Four weeks after the start of the treatment, she developed alopecia. She was continued with sunitinib therapy till progression.

Conclusions: The present case shows a rare metastasis to the ovary and early onset of rare adverse event of alopecia on starting sunitinib therapy. In the presence of confounding factors like hypothyroidism and dandruff, establishing this as an adverse reaction of sunitinib is difficult. This case had a unique metastatic spread with involvement of the bowel, ovary and peritoneal carcinomatosis. Use of adjuvant TKl's after resection of primary tumour in nonmetastatic setting may reduce metastatic rates and increase progression-free survival.
\end{abstract}

\section{Background}

Sunitinib is a novel multitargeted tyrosine kinase inhibitor of vascular endothelial growth factor receptors, platelet-derived growth factor receptors and other RTKs with antitumour and antiangiogenic activity [1]. It is accepted worldwide for the treatment of metastatic renal cell carcinoma (mRCC) and imatinib-resistant gastrointestinal stromal tumours (GIST) [2]. Long-term survival in patients receiving sunitinib for $\mathrm{mRCC}$ is > 2 years with a follow-up of $>6$ years [3]. Treatmentrelated adverse effects (TRAEs) following long-term follow-up included decreased appetite, diarrhoea, dysgeusia, dyspepsia, fatigue, hypertension, mucosal inflammation, nausea, stomatitis and hypothyroidism [4].

\footnotetext{
* Correspondence: manojpandey66@gmail.com

${ }^{1}$ Department of Surgical Oncology, Institute of Medical Sciences, Banaras Hindu University, Varanasi 221005, India

Full list of author information is available at the end of the article
}

Though metastasis is common, metastasis to the ovary is rare with only 34 cases been reported till date $[5,6]$. We present a case of alopecia as a TRAE of sunitinib in a patient of $\mathrm{mRCC}$ to ovary carcinomatosis peritoneii in the early phase of treatment.

\section{Case presentation}

A 22-year-old hypothyroid girl presented with right renal mass (Figs 1, 2 and 3). A metastatic workup was negative. Haematological parameters were normal; however, the patient was found to be hypothyroid with T3 of 93.6, T4 of 4.2 and TSH of 11 . With a diagnosis of $\mathrm{T}_{2} \mathrm{~N}_{0}$, $\mathrm{RCC}$, the patient underwent right radical nephrectomy after correction of her hypothyroid status. At the time of surgery, the thyroid hormone status was T3 of 112, T4 of 14 and TSH of 0.5. Histopathological examination revealed a clear cell carcinoma Fuhrman nuclear grade 4, of the right kidney $\mathrm{pT}_{2 \mathrm{a}} \mathrm{N}_{0}$ (Fig. 4). Gerota's fascia was 


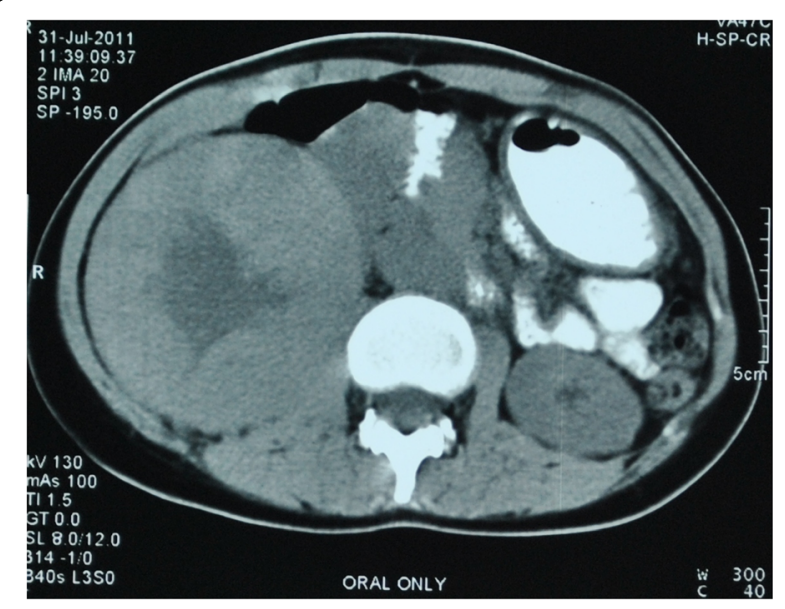

Fig. 1 Computed tomogram showing large mass replacing almost whole of the right kidney with a functioning left kidney

intact, and all resection margins including the renal vein and Gerota fascia were negative. The lymphovascular invasion was present, and the tumour necrosis was also present. Patient made and uneventful recovery and was discharged on the 5 th postoperative day. Six months later, she presented with pain in the abdomen, and examination revealed a right iliac fossa mass. Her thyroid status was again found to be deranged with a T3 of 67 , T4 of 5.9 and TSH of 16 . Imaging revealed metastasis at the ileocolic junction and the ovary (Figs. 5 and 6). After correction of thyroid status (T3-76, T4-11, TSH2.8 ), she underwent an exploratory laparotomy; on laparotomy, multiple peritoneal nodules were found with 4$\mathrm{cm}$ lesion at the ileocolic junction, 3-cm lesion in the right ovary and $1-\mathrm{cm}$ lesion in the left ovary. A right hemicolectomy, and a right oophorectomy with excision of all peritoneal nodules, was carried out. The histopathology was consistent with metastatic clear cell carcinoma; one of the dissected pericolic nodes was also

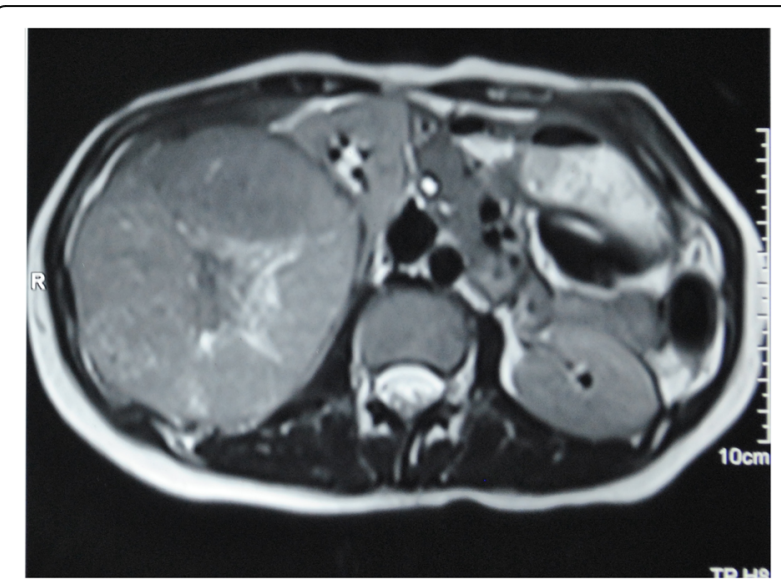

Fig. 2 MR image showing mass in the right kidney

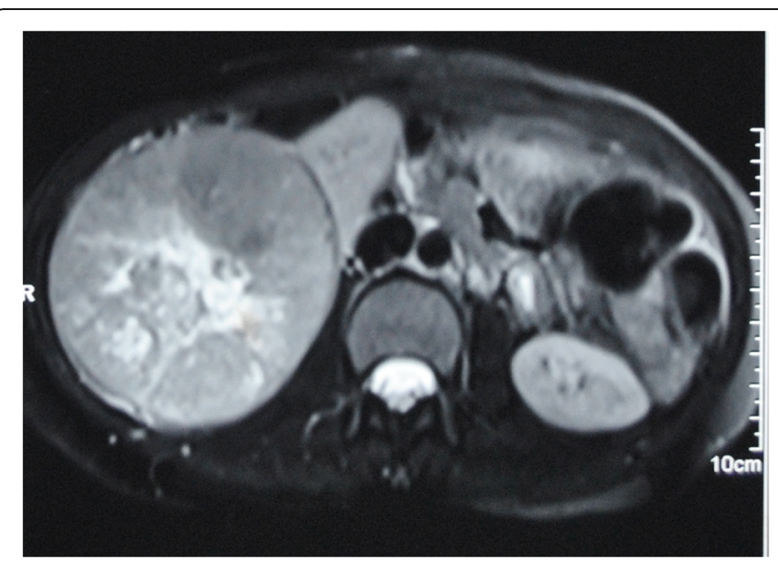

Fig. 3 T2-weighted MR image showing a mass replacing whole of the kidney with no extracapsular invasion

positive (Fig. 7). The metastasis was present on the surface of the resected organs and peritoneum with mucosa of the colon being normal; a good amount of tumour necrosis was also present. She was started on sunitinib therapy. Four weeks after starting the therapy, she developed alopecia. She was referred to her endocrinologist as she was hypothyroid on supplementation, who found the thyroid function to be within normal limits. She was then referred to a dermatologist who found that patient has dandruff and started her on an anti-dandruff treatment. The dandruff got controlled, but the hair fall continued as it was earlier. A diagnosis of sunitinib-induced alopecia was made; this was discussed with the patient, and she made a decision to continue on sunitinib therapy. Eight months after the treatment, she had a progression of disease and ascites and she was offered to shift to mechanistic target of rapamycin (mTOR) inhibitors which she refused. After discussions, she was started on sorafanib $400 \mathrm{mg}$ OD. Two months after starting on

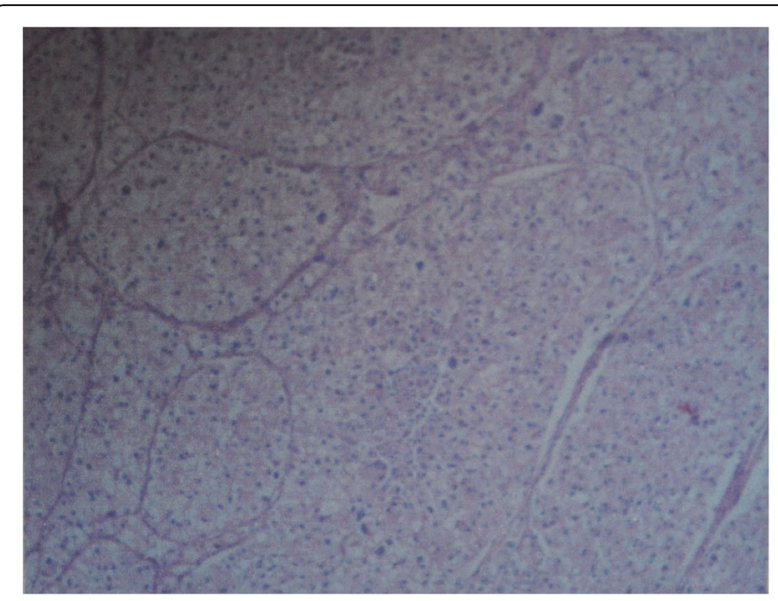

Fig. 4 Photomicrograph showing clear cell carcinoma of the kidney (haematoxylin and eosin $\times 40$ ) 


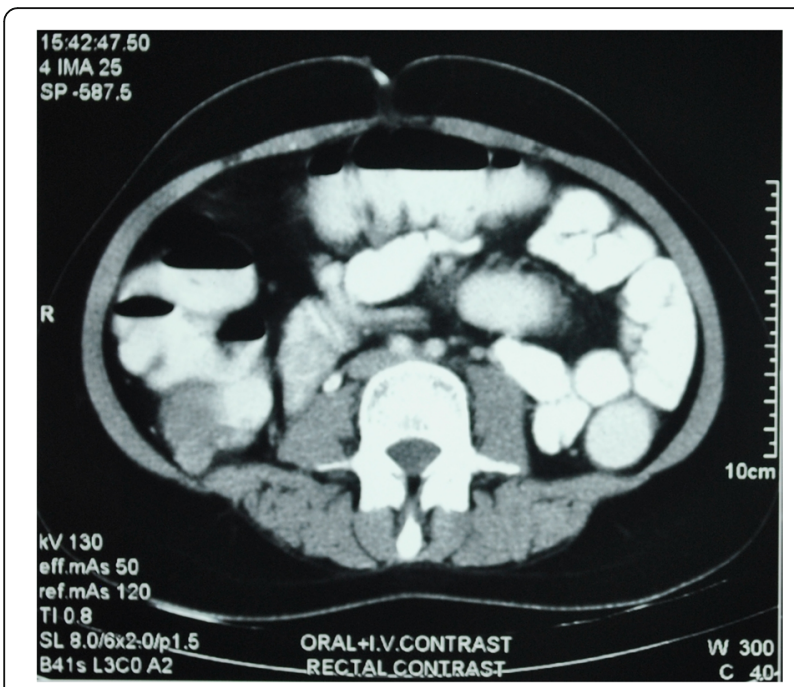

Fig. 5 Computed tomography image showing mass at the ileocolic junction; no recurrence is seen in the renal bed

sorafanib therapy, the patient died of progressive disease at home.

\section{Discussion}

Alopecia is a little discussed side effect of tyrosine kinase inhibitors (TKIs) and is usually milder than that in chemotherapy. A PubMed search carried out in November 2016 using the term ("sunitinib" [Supplementary Concept] OR "sunitinib" [All Fields]) AND ("alopecia" [MeSH Terms] OR "alopecia” [All Fields]) revealed only 13 articles [7-19] of which only five articles [7-11] analysed the adverse effect of sunitinib. Changal et al. reported incidence of alopecia in $13 \%$ of patients treated with sunitinib for mRCC [7]. Another study from China shows alopecia in $34 \%$ of patients [8], while results from other studies by Chan and Lee show alopecia in 6 and

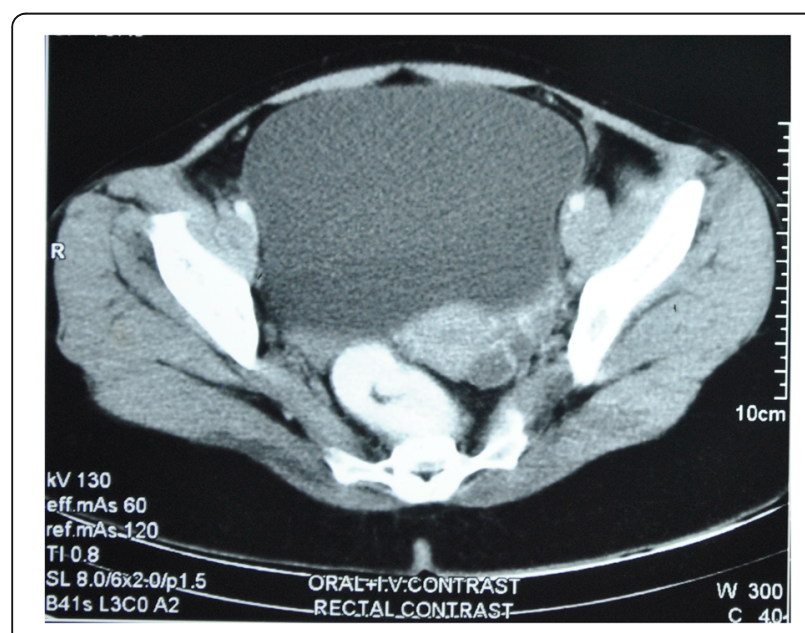

Fig. 6 Computed tomography image showing collection in the uterine cavity with lesion in the left adnexa
$5 \%$ of patients respectively [9, 10]. Pooled analysis of published studies retrieved from various databases by Rosenbaum shows alopecia in $6 \%$ of patients [11]. However, the studies that compared the adverse effect of TKIs show alopecia to be more common in sorafenib (26\%) - and pazopanib (11\%)-treated patients when compared to sunitinib (6\%) [12-14]. Recent pooled analysis of 5739 patients from various trials which analysed longterm TRAE of sunitinib concluded that prolonged sunitinib was not associated with new types or increased severity of TRAEs. Alopecia was not included as an adverse effect in that trail [18]. Our patient developed alopecia within 4 weeks of initiation of sunitinib therapy. Her thyroid status at that time was normal. No other known confounding factor was found. Dermatological and endocrine consultations were done; that too suggested sunitinib as the probable cause of alopecia.

Almost one third of the patients have metastasis at the time of presentation, while others develop metastasis during follow-up. Metastatic spread to the lung, liver, bones and lymph nodes is common in clear cell carcinoma of the kidney. Peritoneal carcinomatosis and metastasis to the bowel and ovary are very rare with only 34 cases of ovarian metastasis being published in PubMedindexed literature till November 2016 [5, 6]. Another PubMed search with term ("carcinoma, renal cell" [MeSH Terms] OR ("carcinoma" [All Fields] AND "renal" [All Fields] AND "cell” [All Fields]) OR "renal cell carcinoma" [All Fields] OR ("renal" [All Fields] AND "cell" [All Fields] AND "carcinoma" [All Fields])) AND (("carcinoma" [MeSH Terms] OR "carcinoma" [All Fields] OR "carcinomatosis” [All Fields]) AND peritonei [All Fields]) was carried out on December 16, 2017, revealed four articles, and none of them were on renal cell carcinoma. However, hand-searching the literature identified 19 instances where peritoneal dissemination had been reported. These can be classified into three subcategories, i.e. first as presentation with disseminated peritoneal disease, second as recurrence after initial nephrectomy [20] and third, most common nowadays, as port site and omental mets after the laparoscopic excision of renal masses. Stavropoulos et al. reported a case who presented with peritoneal metastasis and noted that the incidence of peritoneal metastasis in renal cell carcinoma is about $1 \%$ at autopsy [21]. The first port site metastasis was probably reported for the first time in 2006 by Dhobada et al. [22], while recurrence in peritoneum was reported in 1990 [23]. It is now clear that 1$3 \%$ of all cases of renal cell carcinoma develops peritoneal metastasis and the literature review suggest that transcoelomic spread may be one of the ways RCC disseminates, besides hematogenous and lymphatic dissemination. Though theoretically, peritoneal implantation at the time of surgery could be a possibility and may be a 


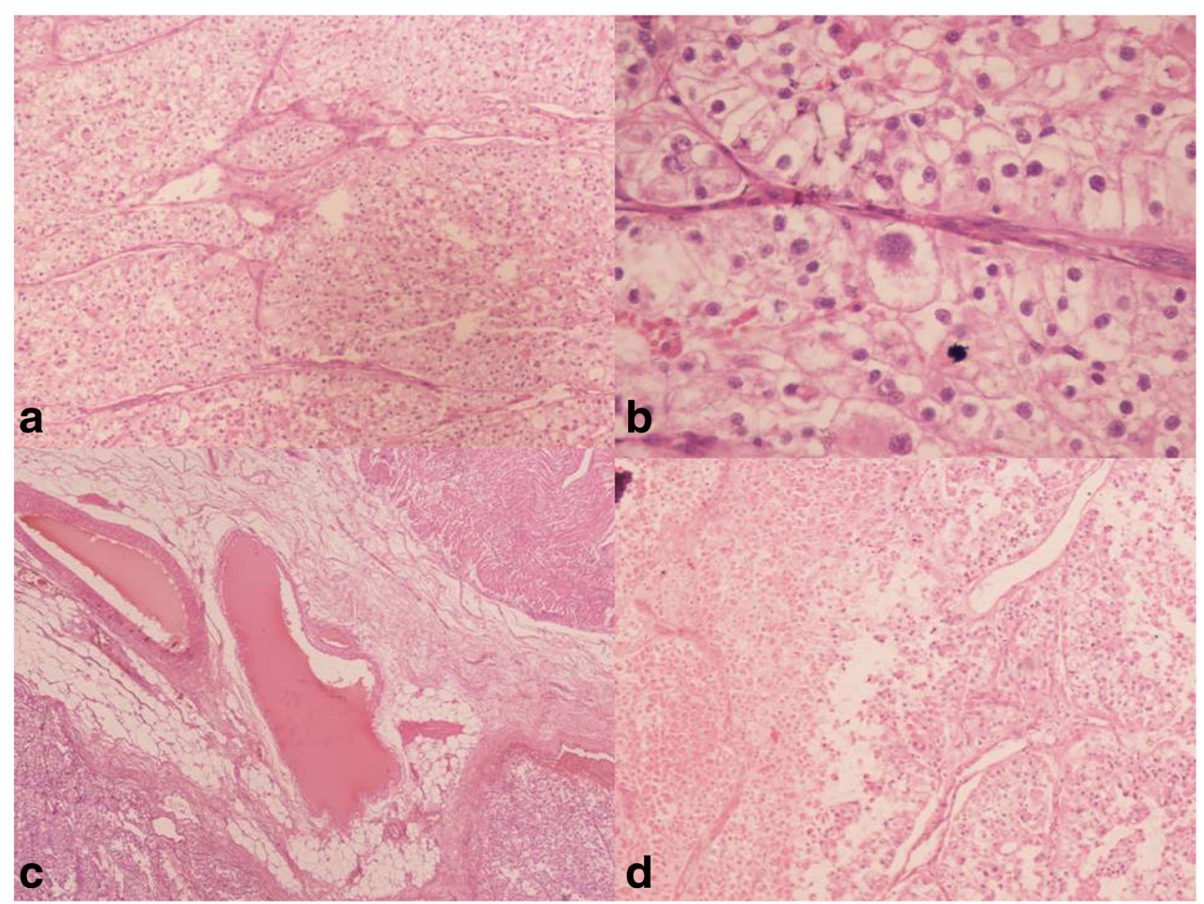

Fig. 7 Photomicrograph of the recurrent tumour. a Low power view showing nests of clear cells (H\&E $\times 40)$. b High power view showing clear cell deposits $(H \& E \times 400)$. c Clear cell deposits in the mesentry with smooth muscle wall on top right and tumour on bottom left (H\&E $\times 40)$. $\mathbf{d}$ Low power view showing necrosis on the left and tumour on the right $(H \& E \times 40)$

reason for port site metastasis, in tumours where Gerota's fascia has been intact and tumour has been confined to the kidney, transcoelomic spread is a possibility. The median survival of patients with metastatic disease is about 4 months while it increases with the use of TKIs and mTOR inhibitors, and the survival depends on the grade of the tumour and prognostic grading criteria that are proposed.

\section{Conclusions}

Alopecia is a dermatological side effect that can also be seen with sunitinib therapy. Though not so rare, this is a little known adverse event of this therapy. In presence of hypothyroidism and dandruff, establishing the cause of alopecia to sunitinib therapy is only by exclusion and correction of the two. Further ovarian metastasis is also rare with only 34 cases been reported till date. This case had unique metastatic spread with involvement of the bowel, ovary and peritoneal carcinomatosis. Use of adjuvant TKIs after resection of primary tumour in nonmetastatic setting may reduce metastatic rates and increase progression-free survival.

\section{Acknowledgements}

The authors acknowledge the contribution of Dr. Hema Malini Iyer, Consultant Pathologist, Lal Pathology, for her valuable contribution.

\section{Funding}

None

\section{Availability of data and materials}

This manuscript reports on a single case, and as per the privacy protection, policy data on a single case cannot be provided without the explicit permission of the patient or his next of kin.

\section{Authors' contributions}

MR prepared the manuscript draft and conducted the literature search. MS collected the data, contributed to the pathological part of the manuscript and edited the content. MP conceived the idea and edited the final manuscript. All authors read and approved the final manuscript.

\section{Ethics approval and consent to participate}

The written informed consent was obtained from the patient for publication of this case report. The copy of the consent is available with the authors.

\section{Competing interests}

The authors declare that they have no competing interests.

\section{Publisher's Note}

Springer Nature remains neutral with regard to jurisdictional claims in published maps and institutional affiliations.

\section{Author details}

'Department of Surgical Oncology, Institute of Medical Sciences, Banaras Hindu University, Varanasi 221005, India. ${ }^{2}$ Lab Head, SRL Religere, Varanasi 221005, India. 
Received: 14 August 2017 Accepted: 1 February 2018

Published online: 06 February 2018

\section{References}

1. Le Tourneau C, Raymond E, Faivre S. Sunitinib: a novel tyrosine kinase inhibitor. A brief review of its therapeutic potential in the treatment of renal carcinoma and gastrointestinal stromal tumors (GIST). Ther Clin Risk Manag. 2007;3(2):341-8.

2. Gore ME, Szczylik C, Porta C, Bracarda S, Bjarnason GA, Oudard S, et al. Safety and efficacy of sunitinib for metastatic renal-cell carcinoma: an expanded-access trial. Lancet Oncol. 2009;10(8):757-63.

3. Molina AM, Jia X, Feldman DR, Hsieh JJ, Ginsberg MS, Velasco S, et al. Longterm response to sunitinib therapy for metastatic renal cell carcinoma. Clin Genitourin Cancer. 2013;11(3):297-302.

4. Porta C, Gore ME, Rini BI, Escudier B, Hariharan S, Charles LP, et al. Longterm safety of sunitinib in metastatic renal cell carcinoma. Eur Urol. 2016; 69(2):345-51.

5. Kostrzewa M, Zyła M, Władziński J, Stetkiewicz T, Stachowiak G, Wilczyński JR. Metastases of renal clear cell carcinoma to ovary-case report and review of the literature. Eur J Gynaecol Oncol. 2015;36(2):219-22.

6. Liang L, Huang H, Dadhania V, Zhang J, Zhang M, Liu J. Renal cell carcinoma metastatic to the ovary or fallopian tube: a clinicopathological study of 9 cases. Hum Pathol. 2016;51:96-102. https://doi.org/10.1016/j. humpath.2015.12.017. Epub 2016 Jan 7

7. Mir MH, Changal KH, Aziz SA, Bhat GM, Lone AR. Sunitinib in metastatic renal cell carcinoma (mRCC): a developing country experience. Do our patients behave differently than the Western patients? Int Urol Nephrol. 2016;48(11):1811-6.

8. Zhao J, Zhu Y, Zhang C, Wang X, He H, Wang H, Wu Y, Zhou W, Shen Z. Sorafenib or sunitinib as postoperative adjuvant therapy for Chinese patients with locally advanced clear cell renal cell carcinoma at high risk for disease recurrence. Urol Oncol. 2013;31(8):1800-5. https://doi.org/10.1016/j. urolonc.2012.04.019. Epub 2012 May 31. PMID: 22658883.

9. Chan A, Tan EH. How well does the MESTT correlate with CTCAE scale for the grading of dermatological toxicities associated with oral tyrosine kinase inhibitors? Support Care Cancer. 2011;19(10):1667-74

10. Lee WJ, Lee JL, Chang SE, Lee MW, Kang YK, Choi JH, Moon KC, Koh JK. Cutaneous adverse effects in patients treated with the multitargeted kinase inhibitors sorafenib and sunitinib. Br J Dermatol. 2009;161(5):1045-51.

11. Rosenbaum SE, Wu S, Newman MA, West DP, Kuzel T, Lacouture ME. Dermatological reactions to the multitargeted tyrosine kinase inhibitor sunitinib. Support Care Cancer. 2008;16(6):557-66.

12. Macdonald JB, Macdonald B, Golitz LE, LoRusso P, Sekulic A. Cutaneous adverse effects of targeted therapies: part I: inhibitors of the cellular membrane. J Am Acad Dermatol. 2015;72(2):203-18.

13. Reyes-Habito CM, Roh EK. Cutaneous reactions to chemotherapeutic drugs and targeted therapies for cancer: part I. Conventional chemotherapeutic drugs. J Am Acad Dermatol. 2014;71(2):203-e1.

14. Biondo A, Alexander H, Khabra K, Pickering L, Gore M, Larkin J. Pazopanibinduced alopecia, an underestimated toxicity?. Front Oncol 2015;5:112 PMID: 26029668.

15. Rini Bl, Escudier B, Tomczak P, Kaprin A, Szczylik C, Hutson TE, Michaelson MD, Gorbunova VA, Gore ME, Rusakov IG, Negrier S. Comparative effectiveness of axitinib versus sorafenib in advanced renal cell carcinoma (AXIS): a randomised phase 3 trial. Lancet. 2011;378(9807):1931-9.

16. De Jonge MJ, Dumez H, Kitzen JJ, Beuselinck B, Verweij J, Courtney R, Battista A, Brega N, Schöffski P. Phase I safety and pharmacokinetic study of SU-014813 in combination with docetaxel in patients with advanced solid tumours. Eur J Cancer. 2011;47(9):1328-35.

17. Hartmann JT, Haap M, Kopp HG, Lipp HP. Tyrosine kinase inhibitors-a review on pharmacology, metabolism and side effects. Curr Drug Metab. 2009; 10(5):470-81.

18. Xiao YY, Zhan P, Yuan DM, Liu HB, Lv TF, Song Y, Shi Y. Chemotherapy plus multitargeted antiangiogenic tyrosine kinase inhibitors or chemotherapy alone in advanced NSCLC: a meta-analysis of randomized controlled trials. Eur J Clin Pharmacol. 2013;69(2):151-9.

19. Robert C, Gimel P. Management of side effects of targeted therapies in renal cancer: cutaneous side effects. Bull Cancer. 2011;98(3 Suppl):S35-46.

20. Acar Ö, Mut T, Sağlıcan Y, Sag AA, Falay O, Selcukbiricik F, Tabak L, Esen T. Isolated omental metastasis of renal cell carcinoma after extraperitoneal open partial nephrectomy: a case report. Int J Surg Case Rep. 2016;21:6-11. https://doi.org/10.1016/j.ijscr.2016.02.008.
21. Stavropoulos NJ, Deliveliotis C, Kouroupakis D, Demonakou M, Kastriotis J, Dimopoulos C. Renal cell carcinoma presenting as a large abdominal mass with an extensive peritoneal metastasis. Urol Int. 1995;54(3):169-70.

22. Dhobada S, Patankar S, Gorde V. Case report: port-site metastasis after laparoscopic radical nephrectomy for renal-cell carcinoma. J Endourol. 2006; 20(2):119-22. discussion 122

23. Orlando G, Rollino R, Iweha C, Andronio D, Marandola P. Solitary subhepatic metastasis of renal adenocarcinoma. Arch Esp Urol. 1990;43(9):1037-8.

\section{Submit your next manuscript to BioMed Central and we will help you at every step:}

- We accept pre-submission inquiries

- Our selector tool helps you to find the most relevant journal

- We provide round the clock customer support

- Convenient online submission

- Thorough peer review

- Inclusion in PubMed and all major indexing services

- Maximum visibility for your research

Submit your manuscript at www.biomedcentral.com/submit
Biomed Central 